\title{
A Renowned, Yet Forgotten Astronomer: Marcel de Kerolyr
}

\author{
André Richardot
}

Observatoire de Sabarat, F-09350 Daumazan-sur-Arize, France

Marcel Bonnemain de Kerolyr was born in 1873 and became a talented professional violinist. He married a singer and acting as accompanist to his wife, toured Europe in the period before the 1914-18 War, even giving a recital before Tzar Nicholas II and the Tzarina. Between tours, they lived in a mansion on the Promenade des Anglais at Nice, and where they entertained a lot. It was in leaving their home, and under their very eyes, that the American dancer Isadora Duncan was the victim of a fatal accident in 1927.

But then catastrophe: his wife lost her voice, and was found to be suffering from chronic anaemia. No more tours, and no more fees. They managed to subsist by selling furniture, pictures and jewellery. De Kerolyr was profoundly depressed and even toyed with the idea of suicide.

He had already visited Nice Observatory, but his enquiring mind also brought him into contact with an amateur, who had retired to Antibes, Georges Raymond, who encouraged and advised him. He acquired some objective lenses and got in touch with a mechanic. He decided to devote the rest of his life to astronomy, particularly to astronomical photography.

They scraped together what money they had and bought a house outside Digne (Alpes de Haute Provence). The site was excellent (without, in those days, lightpollution) and most of the time there was almost perfect atmospheric transparency.

His observatory (illustrated in L'Astronomie, Oct. 1928), had a run-off roof and was constructed of wood and galvanized iron. It contained a home-made mounting, with a fine bronze worm-wheel and worm, but the rest of the mechanical parts (geartrain, transmission and a hand drive requiring one turn per second, was made from Meccano.

The instruments were: a camera with a portrait lens, by Derogy, diameter $130 \mathrm{~mm}, \mathrm{f} / 4.6$; a camera with a Berthiot aerial lens, diameter $120 \mathrm{~mm}, \mathrm{f} / 10$ (both equipped with $13 \times 18$ plate-holders); and a $250-\mathrm{mm}, \mathrm{f} / 15$ guide telescope.

I met him in 1928 and for two years, was at his home three times a week, at least! Mme de Kerolyr, who was then more or less disabled (she weighed $210 \mathrm{~kg}$ !), used to greet me with unfailing kindness and directed me either to the study or to her husband's observatory.

Probably through the intermediary of Mme Gabrielle C. Flammarion, there was some simple agreement between the Lumière laboratories and de Kerolyr, who 
obtained plates, paper and chemicals direct from Lumière.

The results can be seen in the photograph published in L'Astronomie, Oct. 1928. ${ }^{1}$ This photograph of the Milky Way (exposure 2 hours) is crossed by the trail of an exceptionally bright fireball - estimated by Emile Touchet as being magnitude -12 ! The plates were slow: the America nebula is beginning to be visible, but the Pelican has not yet been recorded. A photograph of Messier 31 (L'Astronomie, May 1929 taken in May, 1929), with 7 hours of exposure over three nights, shows that the method of resuming the exposure and ensuring that the star images fall in exactly the same place had been perfected.

In 1930, he sold his house in Digne to my mother, and moved to Forcalquier, $50 \mathrm{~km}$ southwest of Digne, close to Saint-Michel, where the Observatoire de HauteProvence was later to be built. Seeing the results from Digne, particularly those with the Berthiot objective, Ernest Esclanglon (Director of Paris Observatory), André Danjon (Director of Strasbourg and later Paris Observatories) and André Couder felt that they had just the man they needed to test sky conditions on the Forcalquier plateau and its surroundings. André Couder made the optics, and G. Prin the mechanical parts, for a $81-\mathrm{cm}$ testing telescope. Initially, de Kerolyr worked with the instruments from Digne. For a photograph of nebulosity in Orion's belt (L'Astronomie, Sept. 1932) the exposure was 12 hours, in four sessions. The Opta and Super-Opta plates from Lumière were called "ultra-fast", but must have crawled along at about 10 to 15 ASA. Guiding was always by hand and included numerous interruptions.

The Couder-Prin telescope (L'Astronomie, Sept. 1933) was installed in its 8-m diameter dome, close to the de Kerolyrs' villa. Naturally I went there as often as possible, either by train or by bicycle. Many details of this telescope are given in Danjon and Couder's classic Lunettes et Telescopes. He then sold me his equatorial mounting and the Berthiot and Derogy cameras.

In May 1933, L'Astronomie published the first (IC 405) of several plates reproducing deep-sky photographs obtained by de Kerolyr with this near-perfect - and perfectly used - instrument. These plates were expensive to reproduce and, up to the last, published in 1938, were described as "having been paid for by X...". After his death, it was made known that the anonymous donor was Comte Aymard de la Baume Pluvinel.

The observatory was called the "Paris Observatory Astrophysical Out-station". Costs were met by Paris, and de Kerolyr worked there as "observer", with complete liberty of choice as regards subjects and methods. He was not an official employee. This was why, later, and at the instigation of Mme Flammarion, André Danjon and Dr Marc Badel, there were difficulties in getting him a small pension.

Over the months and years, photographs followed one another, and many were published in our society's journal. Some of these photographs were used by de Kerolyr to illustrate Jean Giono's Le Poids du Ciel, 1938. In 1937, the new Palais de la Découverte, built for the Exposition Universelle, showed a collection of them,

1 Regrettably, few of de Kerolyr's plates can be located, and those available for reproduction do not include all the striking ones mentioned in this paper. We strongly recommend that readers should consult the relevant issues of $L^{\prime}$ Astronomie. - Eds. 
crowned by an enlargement of Messier 31 that was 7 metres long, and full of wonderful detail.

The southern part of the America nebula was shown in one photograph ( $L$ 'Astronomie, Nov. 1933). Several points deserve to be mentioned. First, the exposuretime was 20 hours. This brought out details hitherto unknown. The sky background, despite the long exposure, shows no fogging; where it appears slightly illuminated, there is actually faint nebulosity. In some parts the background is completely black. The "ultra-fast" plates of those days that are so very, very slow to us had the advantage of high resolution and high contrast. The faintest stars are about 20 th magnitude, and their size on the original plate is about one-thirtieth of a millimetre. In L'Astronomie 1933, p. 516, de Kerolyr wrote "This shows the optical and mechanical perfection of the equipment, particularly if one considers the length of the exposure, and if one remembers that the plate-holder had to be removed some forty times to ensure that focus was exact (by Foucault testing)." I hardly know which to admire most: the perfection of the telescope, or the skill of the man who was using it!

The last photograph from our "observer", appeared in L'Astronomie for 1938 April. It was obtained by using a Zeiss objective, 130 -mm diameter, collimated by Couder, stopped down to $\mathrm{f} / \mathrm{9}$, and mounted piggy-back on the telescope. It shows the very extended, faint nebulosity around the Pleiades, which with their immediate surroundings are intentionally overexposed, and completely burnt out. But faint nebulosity appears over an enormous area (the photograph covers $9^{\circ} 16^{\prime}$ by $7^{\circ} 14^{\prime}$; north is to the right). The reproduction was made from a composite of two images, one totalling 18 hours of exposure (1937 December 30-31 and 1938 January 1-2) and the other 24 hours on six nights (1938 January 19-25). The equivalent exposure is therefore forty-two hours - and the sky background is still black! Have these faint nebulosities been recaptured with modern photographic materials, which are so sensitive to fogging?

The Berthiot objective (120-mm diameter, f/10) did not remain idle for the first two years at Forcalquier. After several attempts, it captured the first colour photograph of the Green Flash, on a Lumière Autochrome plate. It was reproduced in black-and-white in L'Astronomie, 1932, page 90, illustrating an article by Emile Touchet. Predominantly green starch grains can be seen in the largest plume: the exposure was 0.1 second.

After 1938, the death of his wife and then the war cut de Kerolyr off. I heard nothing of him until 1946, when I received a telegram pleading for me to sell the equatorial mounting back to him. He visited me some days later in Marsillargues (Hérault), accompanied by Dr Marc Badel from Valence. The latter knew (via the S.A.F.) de Kerolyr's reputation, and had visited the "Paris Out-station" at Forcalquier. He had wanted an observatory of his own, and he gave Marcel de Kerolyr the job of bringing it to fruition. The equatorial mount and the Berthiot and Derogy cameras, and some other visual instruments, are reproduced in L'Astronomie, 1947 April.

Silence then falls again. Marc Badel told me that de Kerolyr had been in hospital and then in a rest home on the Côte d'Azur. We believe that he died there in 1969. 
A sad end for an astonishing and very colourful person.

The Société Astronomique de France gave him the following awards: in 1933, the first Dorothea Roberts-Klumpke Award, only just instigated; in 1935, the Camille Flammarion Award; and in 1937, the Dorothea Roberts-Klumpke Award for the second time.

So the Société Astronomique de France honoured Marcel de Kerolyr. We may even say that it adored him; he was compared, and quite rightly, with the finest American astrophotographers, who had far superior instrumentation. And then it forgot him. L'Astronomie never mentioned him again, and never even published an obituary.

\section{References}

Fehrenbach, Ch., "La création de l'Observatoire de Haute Provence" in Histoire et Avenir de l'OHP, OHP, 1987. [De Kerolyr's equipment was illustrated in L'Astronomie, 1928 October, and the Couder-Prin telescope in 1933 September. Photographs taken by the early cameras were published in the issues for 1928 October, 1929 May and 1932 September, while those using the 81-cm appeared at intervals from 1933 May to 1938 April. - Eds] 